\title{
MIOCARDITE CHAGÁSICA CRÔNICA HUMANA: ESTUDO QUANTITATIVO DOS LINFÓCITOS CD4+ E DOS CD8+ NO EXSUDATO INFLAMATÓRIO
}

\author{
Sebastião Tostes Junior, Edison Reis Lopes, Fausto Edmundo Lima Pereira e \\ Edmundo Chapadeiro
}

\begin{abstract}
Em cortes histológicos de fragmentos transmurais congelados da parede livre do ventrículo esquerdo, obtidos em necrópsias de 10 chagásicos crônicos cardiopatas, foram contados os linfócitos $C D 4+e$ os $C D 8+$ do infiltrado miocárdico. As células foram marcadas com anticorpos monoclonais, usando-se a técnica estreptavidina-biotina. Contou-se: 1) os linfócitos em todo o exsudato (LTE) e, separadamente, 2) os linfócitos que estavam em contato ou muito próximos das miocélulas (LCMPM). Foram considerados muito próximos aqueles linfócitos cujos núcleos distavam, das miocélulas, menos que seus próprios menores diâmetros nucleares. Os linfócitos $C D 8+$ foram mais numerosos do que os $C D 4+$, principalmente entre os $L C M P M$. $A$ relação $C D 4 / C D 8$ foi de $0,37 \pm 0,20$ entre os $L T E$, mas foi menor quando considerados apenas os LCMPM $(0,23 \pm 0,11)$. Dentre os LTE, $34 \pm 11 \%$ dos CD8+ (contra $24 \pm 12 \%$ dos CD4+) eram LCMPM. Todas essas diferenças foram estatisticamente significantes. Linfócitos das duas subpopulações foram vistos em intima relação com miocélulas integras ou rotas, e nâo foram observados parasitas nos cortes examinados. Estes achados concordam com a idéia de que a lesão dos miocardiócitos na forma cardiaca da doença de Chagas humana é mediada principalmente por linfócitos T citotóxicos.
\end{abstract}

Palavras-chaves: Tripanosomíase cruzi. Doença de Chagas. Miocardite. Patogênese. Linfócitos $T$.

A caracterização do infiltrado celular da miocardite chagásica crônica humana $(\mathrm{MChCrH})$ pode fornecer informações relevaníes para 0 esclarecimento da patogênese, história natural, terapêutica e prognóstico da doença de Chagas (DCh).

Os métodos convencionais mostram que o exsudato celular na $\mathrm{MChCrH}$ é constituído predominantemente de linfócitos e macrófagos, ao lado de menor número de eosinófilos, plasmócitos, neutrófilos e mastócitos ${ }^{6}$. Mais recentemente, estudos imunohistoquímicos tền demonstrado predomínio de células $\operatorname{CD} 8+{ }^{4} 7$. Em uma dessas pesquisas, Higuchi e cols. ${ }^{4}$ uitilizaram biópsias endomiocárdicas de ventrículo direito, procedimento que apresenta limitações em razão das pequenas dimensões dos fragmentos e da sede em que são colhidos $^{2}$. No outro estudo, Reis e cols. ${ }^{7}$ analisaram

\footnotetext{
Curso de Pós-graduação em Patologia Humana da Faculdade de Medicina do Triângulo Mineiro, Uberaba, MG.

Suporte financeiro: $\mathrm{CNPq}$ e NIH.

Endereço para correspondência: Dr. Ssbastião Tostes Junior. Curso de Pós-graduação em Patologia Humana, Hospital Escola. R. Getúlio Guaritá 130, 38025-440 Uberaba, MG. Recebido para publicação em 05/04/94.
}

amostras transmurais do ventrículo esquerdo e do septo interventricular.

Com a finalidade de procurar mais elementos que pudessem auxiliar no esclarecimento do papel dos linfócitos T na gênese das lesões das miocélulas cardíacas na DCh, nos pareceu de interesse ampliar os estudos imunohistoquímicos dessas células do exsudato da $\mathrm{MChCrH}$. Para isto, em amostras transmurais do ventrículo esquerdo, quantificamos os linfócitos CD4+ e os CD8 + não só de todo o infiltrado, mas também, separadamente, os que se encontravam em contato ou muito próximos dos miocardiócitos.

\section{MATERIAL E MÉTODOS}

Pacientes e obtenção dos fragmentos. Fragmentos de ventrículo esquerdo foram obtidos em necrópsias completas de 10 chagásicos crônicos cardiopatas - com insuficiência cardíaca congestiva e/ou arritmias - provenientes do Hospital Escola da Faculdade de Medicina do Triângulo Mineiro e do Posto Médico Legal de Uberaba, cujos dados se encontram na Tabela 1. 
Tostes Junior S, Lopes ER, Pereira FEL, Chapadeiro E. Miocardite chagásica crônica humana: estudo quantitativo dos linfócitos CD4+e dos CD8+ no exsudato inflamatório. Revista da Sociedade Brasileira de Medicina Tropical 27:127-134, jul-set, 1994.

Tabela 1 - Dados dos pacientes, todos cardiopatas, brancos e do sexo masculino.

\begin{tabular}{|c|c|c|c|c|c|c|}
\hline Caso & Caso & $\begin{array}{l}\text { Peso do coração } \\
\text { (gramas) }\end{array}$ & ICC & $\begin{array}{l}\text { Mega- } \\
\text { esôfago }\end{array}$ & $\begin{array}{l}\text { Mega- } \\
\text { cólon }\end{array}$ & Outros achados significativos \\
\hline 1 & 46 & 190 & - & + & - & $\begin{array}{l}\text { broncopneumonia, desnutrição, } \\
\text { infarto cerebral }\end{array}$ \\
\hline 2 & 52 & 480 & + & - & - & HAS, infarto cerebral antigo \\
\hline 3 & 57 & 580 & + & - & - & tromboembolismo pulmonar \\
\hline 4 & 50 & 450 & - & + & - & - \\
\hline 5 & 38 & 450 & + & - & - & - \\
\hline 6* & 24 & 350 & - & - & - & - \\
\hline 7 & 40 & 420 & + & - & - & $\begin{array}{c}\text { broncopneumonia, cirrose hepática, } \\
\text { etilismo crônico }\end{array}$ \\
\hline 8 & 45 & 470 & + & - & + & caquexia \\
\hline 9 & 38 & 240 & + & - & - & $\begin{array}{l}\text { broncopneumonia, infarto cerebral } \\
\text { antigo, pielonefrite aguda bilateral }\end{array}$ \\
\hline 10 & 52 & 410 & - & + & - & - \\
\hline Média & 45 & 404 & & & & \\
\hline Desvio padrăo & 11 & 116 & & & & \\
\hline Mediana & 45 & 435 & & & & \\
\hline
\end{tabular}

$\mathrm{ICC}=$ Insuficiência cardíaca congestiva presente em algum momento da vida.

$*=$ morte súbita inesperada.

$+=$ presente.

- = ausente.

HAS = hipertensão arterial sistêmica.

O diagnóstico de DCh baseou-se nos dados clínicos e anatomopatológicos macro e microscópicos e nas reações sorológicas (fixação de complemento, hemaglutinação e imunofluorescência) realizadas no sangue e/ou no líquido pericárdico.

As necrópsias foram realizadas imediatamente após a comprovação do óbito e o preenchimento das formalidades legais para sua execução; quando necessário, os cadáveres foram conservados em câmara frigorífica a $4^{\circ} \mathrm{C}$.

Os fragmentos foram retirados da porção lateral da parede livre do ventrículo esquerdo, na junção dos terços superior e médio, em toda espessura exceto as trabéculas cárneas, e embalados e colocados em nitrogênio líquido, 3 a 10 horas após a morte.

Imunohistoquímica. Utilizamos a técnica estreptavidina-biotina, com os anticorpos monoclonais murinos "DaKoT4", código M716, e “DaKoT8", código M707. O anticorpo "DaKoT4" marca células $T$ auxiliares/indutoras, alguns monócitos do sangue periférico, alguns macrófagos e células de Langerhans ${ }^{1}$. O anticorpo "DaKoT8" marca células $\mathrm{T}$ citotóxicas/supressoras e células citotóxicas naturais 1 . Resumidamente, cortes de 6 micrômetros de espessura eram obtidos no criostato, secados ao ar, fixados em acetona e embalados e armazenadas a $-70^{\circ} \mathrm{C}$. Uma a quatro semanas após, eram submetidos à coloração, sendo todos os procedimentos realizados à temperatura ambiente. Primeiramente eram incubados por 15 minutos com um dos anticorpos monoclonais, diluídos 1:10 em TBS pH 7,6. Continuava-se o procedimento com o "kit" para coloração rápida "Dako", código K687. Os cortes eram sucessivamente incubados com: 1) imunoglobulina biotinilada anti-imunoglobulina de camundongo; 2) estreptavidina ligada a fostatase alcalina e 3) uma mistura de tampão tris, naftol fosfato (substrato), fucsina (cromógeno) e acelerador. A seguir, os cortes eram contracorados com hematoxilina de Gill ("Sigma") e montados. Como controle positivo foi usado um corte de linfonodo obtido de necrópsia, em condições semelhantes às do coração, e como controles negativos um corte desse linfonodo e um de coração 
Tostes Junior S, Lopes ER, Pereira FEL, Chapadeiro E. Miocardite chagásica crônica humana: estudo quantitativo dos linfócitos CD4+e dos CD8+ no exsudato inflamatório. Revista da Sociedade Brasileira de Medicina Tropical 27:127-134, jul-set, 1994.

de cada caso, os quais recebiam TBS ao invés do anticorpo monoclonal.

Como resultado dessa técnica de coloração, as células portadoras dos antígenos pesquisados mostram citoplasmas densamente avermelhados (Figuras 3A-3F).

Quantificação dos Linfócitos CD4+e dos $C D 8+$. Foi feita com a ocular integradora Zeiss II (Figura 1), aumento de 400 vezes, e simultaneamente através de dois sistemas em cada campo. No sistema 1 foram contadas as células que estavam dentro do quadrado $\left(1,4 \times 10^{-2} \mathrm{~mm}^{2}\right)$ ou que eram superpostas ou tangenciadas por seus lados; no sistema 2 foram contadas as células superpostas ou tangenciadas pelas barras horizontais com traços verticais (Figuras 2 e $3 \mathrm{~A}$ ).

Contava-se os linfócitos CD4+ e os CD8+ inicialmente de todo o infiltrado e, posteriormente, apenas. aqueles que estavam em contato ou muito próximos das miocélulas. Foram considerados muito próximos os linfócitos cujos núcleos distavam, das miocélulas, menos que seus próprios menores diâmetros nucleares (Figura 3B).

Em cada caso a objetiva era colocada no centro do corte e eram contadas as células em 100 campos obtidos por movimentos horizontais e verticais alternados, sendo desprezados aqueles em que as miocélulas ocupavam menos da metade da área de contagem.

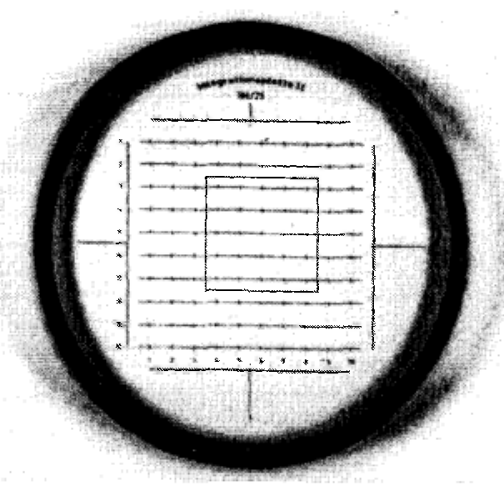

Figura 1 - Ocular integradora ZEISS II, composta de quadrado cujos lados medem $0,12 \mathrm{~mm}$ e de barras horizontais cruzadas por traços verticais.
A contagem em 100 campos foi realizada três vezes, não imediatamente consecutivas, em cada corte, obtendo-se daí o número médio dos subtipos de linfócitos por campo em cada caso. Com esses dados foram calculados os totais dos linfócitos $\mathrm{CD} 4+$ e dos $\mathrm{CD} 8+$, e a relação $\mathrm{CD} 4 / \mathrm{CD} 8$, em cada caso. Calculamos também as porcentagens dos subtipos de linfócitos, do infiltrado miocárdico em geral, que estavam em contato ou muito próximos das miocélulas, através da comparação dos números médios, por campo, de cada tipo e de cada caso. Determinou-se as médias, os desvios padrões e as medianas dos dados obtidos.

Análise estatistica. Foram utilizados o teste " $t$ " de Student e o teste de Wilcoxon, ambos a um nível de significância de $5 \%$.

\section{RESULTADOS}

Em todos os casos o miocárdio apresentava inflamação e fibrose, que variaram de moderada a severa, e não foram observados parasitas nos cortes examinados.

Não houve diferenças estatisticamente significantes entre os valores dos dois sistemas de contagem, e por isso nos limitaremos a apresentar os dados obtidos através do sistema de barras horizontais, expostos nas Tabelas 2, 3 e 4 .

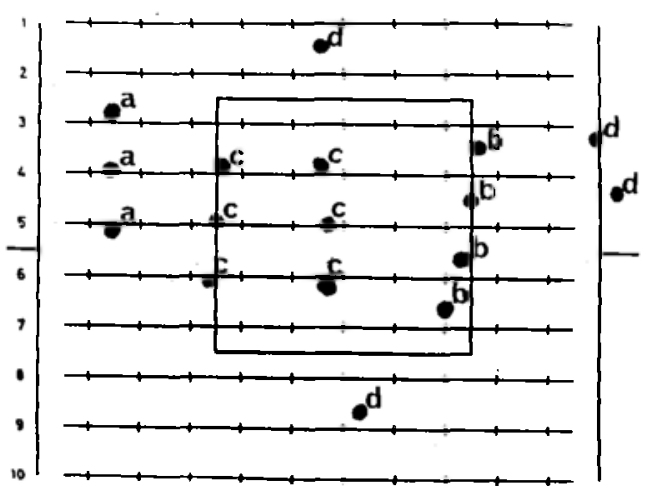

Figura 2 - Ilustração da contagem de células: a) apenas no sistema de barras horizontais; $b$ ) somente no sistemado quadrado; c) nos dois sistemas; d) células não contadas. 
Tostes Junior S, Lopes ER, Pereira FEL, Chapadeiro E. Miocardite chagásica crônica humana: estudo quantitativo dos linfócitos CD4+e dos CD8+ no exsudato inflamatório. Revista da Sociedade Brasileira de Medicina Tropical 27:127-134, jul-set, 1994.
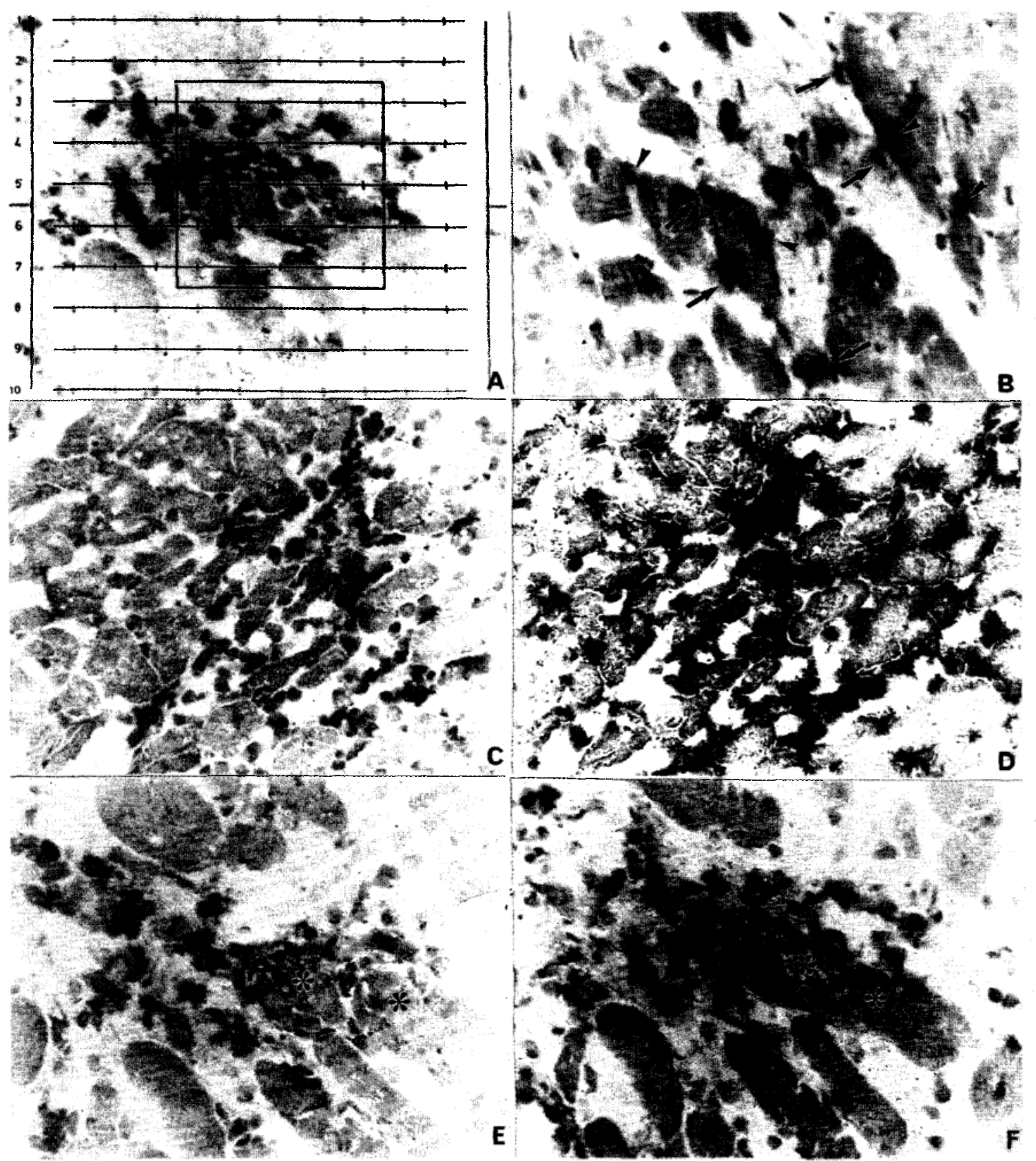

Figura 3 - Linfócitos do infiltrado miocárdico fenotipificados com anticorpos monoclonais e técnica estreptavidinabiotina (aumentos de 400x). A) montagem fotográfica mostrando linfócitos $C D 8+$ vistos com a ocular integradora; B) linfócitos $C D 8+$ com destaque para os que estão em contato (cabeças de seta) ou muito próximos (setas) das miocélulas; C) e D) dois cortes próximos, com linfócitos $C D 4+(C)$ e $C D 8+(D)$ intimamente associados a miocélulas, a maioria delas sem lesóes evidentes; $E$ ) e F) dois cortes próximos, com linfócitos $C D 4+(E)$ e $C D 8+(F)$ intimamente associados a miocélula em destruição (asteriscos). 
Tostes Junior S, Lopes ER, Pereira FEL, Chapadeiro E. Miocardite chagásica crônica humana: estudo quantitativo dos linfócitos CD4 + e dos CD8+ no exsudato inflamatório. Revista da Sociedade Brasileira de Medicina Tropical 27:127-134, jul-set, 1994.

Tabela 2 - Linfócitos Tdo infiltrado miocárdico. Números médios das subpopulações e do total, por campo, e relações $C D 4 / C D 8$.

\begin{tabular}{llccc}
\hline & \multicolumn{3}{c}{ Barras horizontais } \\
\cline { 2 - 4 } Caso & \multicolumn{3}{c}{ números médios por campo } & $\begin{array}{c}\text { relação } \\
\text { CD4/CD8 }\end{array}$ \\
\cline { 2 - 4 } 1 & CD4* & CD8* & Total** & 0,46 \\
2 & 1,38 & 2,99 & 4,37 & 0,62 \\
3 & 1,63 & 2,63 & 4,26 & 0,38 \\
4 & 0,53 & 1,42 & 1,95 & 0,71 \\
5 & 1,07 & 1,51 & 2,58 & 0,16 \\
6 & 0,31 & 1,90 & 2,21 & 0,36 \\
7 & 1,12 & 3,13 & 4,25 & 0,36 \\
8 & 0,51 & 1,41 & 1,91 & 0,10 \\
9 & 0,15 & 1,51 & 1,66 & 0,15 \\
10 & 0,06 & 0,39 & 0,45 & 0,37 \\
\hline Média & 1,39 & 3,71 & 5,10 & 0,37 \\
Desvio padrão & 0,81 & 2,06 & 2,87 & 0,20 \\
Mediana & 0,57 & 1,02 & 1,51 & 0,37 \\
\hline
\end{tabular}

* Os números médios dos linfócitos CD`e dos CD8 positivos foram obtidos pela média após três contagens de cada subpopulaçāo em 100 campos, com aumento de 400 vezes ao microscópio.

** Resultados das somas das duas colunas anteriores, exceto as médias, os desvios padrões e as medianas.

Analises estatisticas: 1. Comparação entre o número de linfócitos CD4+ e o de CD8+ (teste "t" de Student para populações não correlatas) - o número por campo de linfócitos $C D 8+$ foi maior que o de $C D 4+(p=0,0045)$.

Tabela 3 - Linfócitos $T$, do infiltrado miocárdico, em contato ou muito próximos das miocélulas*. Nümeros médios das subpopulações e do total, por campo, e relações CD4/CD8.

\begin{tabular}{lcccc}
\hline & \multicolumn{3}{c}{ Barras horizontais } \\
\cline { 2 - 4 } Caso & \multicolumn{3}{c}{ números médios por campo } & relação \\
\cline { 2 - 4 } 1 & CD4** & CD8** & Total*** & CD4/CD8 \\
\hline 2 & 0,29 & 0,84 & 1,13 & 0,35 \\
3 & 0,14 & 0,68 & 0,83 & 0,21 \\
4 & 0,12 & 0,30 & 0,41 & 0,39 \\
5 & 0,19 & 0,48 & 0,67 & 0,40 \\
6 & 0,12 & 0,75 & 0,87 & 0,16 \\
7 & 0,24 & 1,57 & 1,81 & 0,15 \\
8 & 0,13 & 0,68 & 0,81 & 0,19 \\
9 & 0,04 & 0,43 & 0,47 & 0,09 \\
10 & 0,03 & 0,18 & 0,21 & 0,17 \\
\hline Média & 0,17 & 0,71 & 0,87 & 0,24 \\
Desvio padrão & 0,15 & 0,66 & 0,81 & 0,23 \\
Mediana & 0,08 & 0,38 & 0,44 & 0,11 \\
\hline
\end{tabular}

* Foram considerados muito próximos os linfócitos cujos núcleos distavam, das miocélulas, menos que seus próprios menores diâmetros nucleares.

** Os números médios dos linfócitos CD4+ e dos CD8 + foram obtidos pela média após três contagens de cada subpopulação em 100 campos, com aumento de 400 vezes ao microscópio.

*** Resultados das somas das duas colunas anteriores, exceto as médias, os desvios padrōes e as medianas. Analises estatísticas: 1. Comparação entre 3 múmero de linfócitos CD4 + e o de CD8 + (teste "t" de Student para populações não correlatas) - o número por campo de linfócitos $\mathrm{CD} 8+$ foi maior que o de $\mathrm{CD} 4+(\mathrm{p}=0,0025)$. 
Tostes Junior S, Lopes ER, Pereira FEL, Chapadeiro E. Miocardite chagásica crônica humana: estudo quantitativo dos linfócitos CD4+ e dos CD8+ no exsudato inflamatório. Revista da Sociedade Brasileira de Medicina Tropical 27:127-134, jul-set, 1994.

Tabela 4 - Porcentagens dos linfócitos CD4 e dos CD8 positivos, do infiltrado miocárdico, que estavam em contato ou muito próximos das miocélulas*.

\begin{tabular}{lll}
\hline Caso & CD4 & CD8 \\
\hline 1 & 21 & 28 \\
2 & 09 & 26 \\
3 & 22 & 21 \\
4 & 18 & 32 \\
5 & 39 & 40 \\
6 & 21 & 50 \\
7 & 26 & 49 \\
8 & 27 & 28 \\
9 & 50 & 46 \\
10 & 12 & 19 \\
\hline Média & 24 & 34 \\
Desvio padrão & 12 & 11 \\
Mediana & 22 & 30 \\
\hline
\end{tabular}

* As porcentagens em cada caso foram calculadas pela comparação dos respectivos números médios, por campo, das Tabelas 2 e $3\left(\mathrm{n}^{\circ}\right.$ médio Tabela $3 \times 100 / \mathrm{n}^{\circ}$ médio Tabela 2).

Analise estatistica: (teste de Wilcoxon) - A porcentagem de linfocitos CD8 + foi maior do que a de CD4+ $(p=0,041)$.
Representação simplificada e esquemática dos resultados encontra-se na Figura 4.

Linfócitos das duas subpopulações foram encontrados em íntima associação com miocélulas morfologicamente integras (Figuras 3C e 3D) ou em destruição (Figuras 3E e 3F).

\section{DISCUSSÃo}

Nossos resultados demonstram que na $\mathrm{MChCrH}$ parte do exsudato é constituído por células CD4+ e por células $\mathrm{CD8}+$, sendo estas últimas mais numerosas. Obtivemos relação CD4/CD8 de 0,37 $\pm 0,20$ em amostras transmurais de ventrículo esquerdo, muito próxima à de $0,36 \pm 0,03$ observada por Reis e cols. ${ }^{7}$ em fragmentos transmurais de ventrículo esquerdo e do septo interventricular. Valor semelhante foi também obtido por Higuchi e cols. ${ }^{4}$, que observaram relação CD4/CD8 de $0,3 \pm$ 0,2 em biópsias endomiocárdicas de ventrículo direito. Portanto, as amostras de ventrículo direitó, utilizadas por essa autora, parecem ser representativas do miocárdio ventricular do

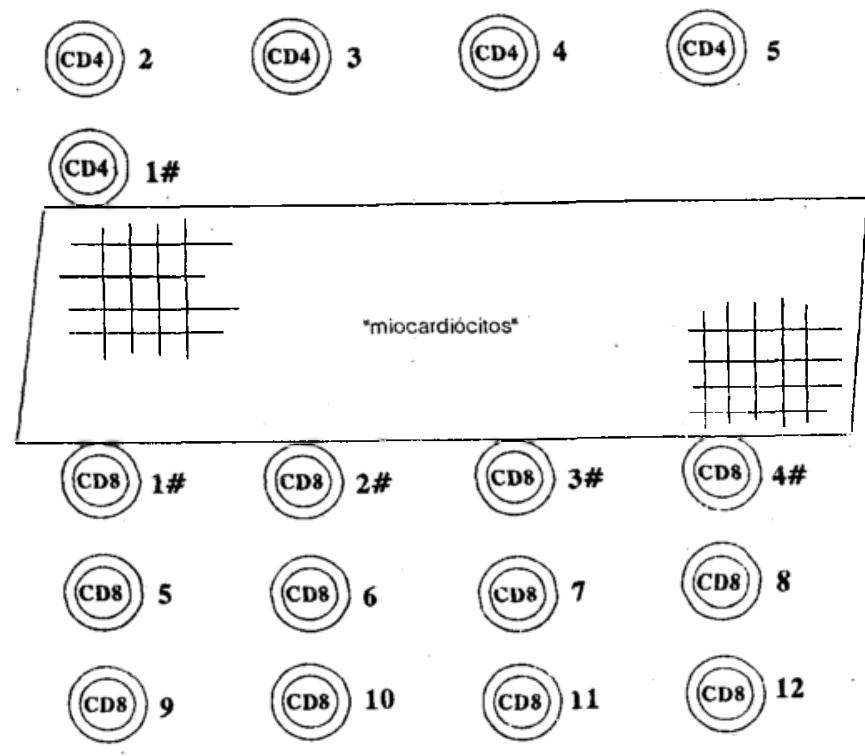

Figura 4 - Representação esquemática dos resultados. A relą̧̃o CD4/CD8 no infiltrado miocárdico foi de 0,37, o que significa que, para cada 17 linfócitos CD4+ ou $C D 8+$, aproximadamente 5 eram $C D 4+$ e 12 eram $C D 8+$. Vinte e quatro por cento dos CD4+ (aproximadamente um em cada cinco) e 34\% dos CD8+ (aproximadamente quatro em cada doze) estavam em contato ou muito próximos das miocélulas. Nesta localização, a relação CD4/CD8 foi de 0,24 (aproximadamente um linfócito CD4+ para quatro CD8+).

\# Linfócitos em contato ou muito próximos dos miocardiócitos. 
Tostes Junior S, Lopes ER, Pereira FEL, Chapadeiro E. Miocardite chagásica crônica humana: estudo quantitativo dos linfócitos CD4+ e dos CD8+ no exsudato inflamatório. Revista da Sociedade Brasileira de Medicina Tropical 27:127-134, jul-set, 1994.

chagásico crônico no que se refere à relação CD4/ CD8 no exsudato inflamatório. Cabe ressaltar que os números absolutos de linfócitos, por nós constatados no presente estudo, diferem dos relatados por Higuchi e cols. ${ }^{4}$ e por Reis e cols. ${ }^{7}$. Isto se deve a que, nestes três trabalhos, foram empregadas metodologias diversas para contagem das células.

Por outro lado, nossa observação da presença de linfócitos CD8 + em contato com miocardiócitos em destruição sugere fortemente uma ação patogênica dessas células na MChCr. Em concordância com essa idéia, verificamos que a fração $\mathrm{CD} 8+$ dos linfócitos fenotipificados foi maior na intimidade dos miocardiócitos (CD4/CD8 $=0,23 \pm 0,11$ ) do que em todo o exsudato $(\mathrm{CD} 4 / \mathrm{CD} 8=0,37 \pm$ $0,20)$, e que $34 \pm 11 \%$ dos linfócitos CD8 + (contra $24 \pm 12 \%$ dos $\mathrm{CD} 4+$ ) do infiltrado inflamatório estavam em contato ou muito próximos das miocélulas cardíacas. Ademais, além das células $\mathrm{CD} 8+$ constituírem a maior parte do exsudato ${ }^{47} \mathrm{e}$ expressarem Granzima $A^{7}$, que é um marcador de citotoxicidade em linfócitos $\mathrm{T}$, a expressão de antígenos de classe I do complexo maior de histocompatibilidade (CHPI) nas miocélulas está aumentada ${ }^{8}$, propiciando a atividade citotóxica desses linfócitos. Há, portanto, evidências de que a lesão dos miocardiócitos na forma cardiaca da doença de Chagas crônica humana é mediada principalmente por linfócitos $\mathrm{T}$ citotóxicos, via CHPI.

No entanto, estas avaliações imunohistoquímicas não permitem concluir que os achados sejam os mesmos em todo o miocárdio. Por isso, nos parece necessário que novos estudos sejam realizados naqueles locais onde o $T$. cruzi ou seus antígenos estão presentes, inclusive porque tem sido demonstrado parasitismo cardíaco em número apreciável de casos ${ }^{35}$. Além disso, seria também fundamental que estudos similares fossem feitos em outras estruturas, como por exemplo, nos músculos liso e esquelético, no sistema nervoso autônomo etc. É importante ressaltar que estes conhecimentos poderiam auxiliar no esclarecimento da patogênese da DCh e, por conseguinte, na sua orientação terapêutica.

\section{SUMMARY}

Myocardial exsudate $C D 4+$ and $C D 8+$ lymphocytes were counted in transmural left ventricular free wall frozen sections taken from 10 necropsied chronic cardiac chagasic patients. The cells were labeled with monoclonal antibodies using a streptavidin-biotin technique. We counted: 1) lymphocytes in the total exsudate (LTE) and, separately, 2) the lymphocytes touching or very near to myocells (LTVMM). Lymphocytes were considered very near whenever their own nuclear shortest nuclear diameter was larger than their distance from myocells. $C D 8+$ lymphocytes were more numerous than CD4+ lymphocytes, especially among the LTVNM. The LTE CD4/CD8 ratio was $0,37 \pm 0,20$, but the LTVNM CD4/CD8 ratio was smaller $(0,23 \pm 0,11)$. Among the LTE, $34 \pm 11 \%$ of CD $8+$ (against $24 \pm 12 \%$ of $C D 4+)$ were LTVNM. All these differences were statistically significant. Both subtypes of T-lymphocytes were found to have an intimate relationship with both ruptured and unruptured myocells, and parasites were not seen. These findings are in accordance with the idea that the myocardial cell lesions in the cardiac form of human Chagas' disease are mediated mainly by $T$ cytotoxic lymphocytes.

Key-words: Trypanosomiasis cruzi. Chagas. disease. Myocarditis. Pathogenesis. T lymphocytes.

\section{REFERÊNCIAS BIBLIOGRÁFICAS}

1. Chan JKC, Ng CS, Hui PK. A simple guide to the terminology and application of leucocyte monoclonal antibodies. Histopathology 12:461-480, 1988.

2. Chow LH, Ye Y, Linder J, McManus BM. Phenotypic analysis of infiltrating cells in human myocarditis. Archives of Pathology and Laboratory Medicine 113:1357-1362, 1989.

3. Higuchi ML, Brito T, Reis MM, Barbosa A, Bellotti G, Pereira-Barreto AC, Pilleggi F. Correlation between Tripanosoma Cruzi parasitism and myocardial inflammatory infiltrate in humam chronic chagasic myocarditis: light microscopy and immunohistochemical findings. Cardiovascular Pathology 2:101-106,1993.

4. Higuchi ML, Gutierrez PS, Aiello VD, Palomino S, Bocchi E, Kalil J, Bellotti G, Pilleggi F. Immunohistochemical characterization of infiltrating cells in human chronic chagasic myocarditis: comparison with myocardial rejection process. Virchows Archives A, Pathological Anatomy and Histopathology 423:157-160, 1993. 
Tostes Junior S, Lopes ER, Pereira FEL, Chapadeiro E. Miocardite chagásica crônica humana: estudo quantitativo dos linfócitos CD4+e dos CD8+ no exsudato inflamatório. Revista da Sociedade Brasileira de Medicina Tropical 27:127-134, jul-set, 1994.

5. Jones EM, Colley DG, Tostes Jr S, Lopes ER, Vnencak Jones CL, McCurley TL. Amplification of a Trypanosoma cruzi DNA sequence from inflammatory lesions in human chagasic cardiomyopathy. The American Journal of Tropical Medicine and Hygiene 48:348-357, 1993.

6. Lopes ER, Chapadeiro E, Tafuri WL, Prata AR. Patologia das principais doenças tropicais no Brasil. Doença de Chagas. In: Lopes ER, Chapadeiro E, Raso P, Tafuri WL (eds) Bogliolo Patologia. $4^{\mathrm{a}}$ edição. Guanabara Koogan, Rio de Janeiro p.1047$1065,1987$.

7. Reis DD, Jones E, Tostes JrS, Lopes ER, Chapadeiro
E, Gazinelli G, Colley DG, McCurley TL. Expression of MHC antigens and adhesion molecules in hearts of patients with chronic Chagas' disease. The American Journal of Tropical Medicine and Hygiene 49:192-200,1993.

8. Reis DD, Jones E, Tostes Jr S, Lopes ER, Gazinelli G, Colley DG, McCurley TL. Characterization of inflammatory infiltrates in chronic chagasic myocardial lesions: presence of TNF-alfa ${ }^{+}$cells and dominance of granzime $\mathrm{A}+, \mathrm{CD} 8+$ lymphocytes. The American Journal of Tropical Medicine and Hygiene 48:637-644,1993. 